Longitudinal Links between Perfectionism and Depression in Children

Master's Thesis

Marielle Asseraf

M.A. Educational Counselling

University of Ottawa

Thesis supervisor: Dr. Tracy Vaillancourt

Thesis committee:

Dr. David Trumpower (chair)

Dr. David Smith

Dr. Jessica Whitley

Author's Note

This study was supported by grants from the Canadian Institutes for Heath Research, Social Sciences and Humanities Research Council of Canada (Community-University Research Alliance; www.mac-cura.ca), and Fonds québécois de la recherche sur la société et la culture (FQRSC).

(C) Marielle Asseraf, Ottawa, Canada, 2013 


\begin{abstract}
The temporal relationship between two types of perfectionism- self-oriented perfectionism (SOP) and socially prescribed perfectionism (SPP) — and depressive symptoms was examined in a sample of 653 children across Grades 6 (depressive symptoms only), 7, and 8. A vulnerability model, in which perfectionism affects depressive symptoms, was compared to a scar model, in which depressive symptoms affects perfectionism, and to a reciprocal-causality model, in which both constructs concurrently affect each other across time. Cross-lagged paths analyses using structural equation modeling supported a scar model where increases in depressive symptoms lead to increases in SPP, but not SOP. The findings applied to both boys and girls. Results suggest that in childhood, depressive symptoms increase the perception that others are expecting excessively high standards from oneself and the need to satisfy this perception.
\end{abstract}




\section{Longitudinal Links between Perfectionism and Depression in Children}

One of the most common mental health difficulties that children and adolescents struggle with is depression, with approximately $16 \%$ of girls and $8 \%$ of boys meeting diagnostic criteria for this disorder (Merikangas et al., 2010). These high prevalence rates are disconcerting because mental health difficulties can negatively affect a variety of areas of functioning including physical health (Feldman, Ortega, McQuaid, \& Canino, 2006; Scott et al., 2011), school achievement (Fröjd et al., 2008), family relationships (Huang et al., 2005), and social functioning (Kupersmidt, Coie, \& Dodge, 1996). Often, mental health issues persist into adulthood if left untreated. For example, in one study, $50 \%$ of children with major depression continued to experience recurrences in adulthood (Kessler, Avenevoli, \& Merikangas, 2001) and in another study, $75 \%$ of adults with psychological disorders including major depression reported that their symptoms began in childhood or adolescence (Weisz, 1998). Because experiencing depression early in childhood can cause detrimental short- and long-term consequences, it is essential to identify factors associated with this disorder. This could lead to earlier diagnosis and more efficacious treatments of depression.

One robust correlate of depression is the personality style of perfectionism which has been shown to be associated with depression in children and adolescents (e.g., Hewitt et al., 2002; Huggins, Davis, Rooney, \& Kane, 2008), as well as adults (e.g., Flett, Hewitt, Blankstein, \& Mosher, 1995; Hewitt \& Flett, 1991a). Although depression and perfectionism are correlated across the lifespan, little is known about the temporal sequence between perfectionism and depression, especially in childhood. Moreover, most of our knowledge about depression and perfectionism stems from the adult literature which suggests that perfectionism is a vulnerability, or risk factor, for depression (vulnerability model; Hewitt, Flett, \& Ediger, 1996; Sherry, 
Mackinnon, Macneil, \& Fitzpatrick, 2012). There are, however, some studies that have demonstrated that perfectionism can also be an outcome of depression (scar model; Cox \& Enns, 2003), or shares a reciprocal relationship with depression (reciprocal-causality model; McGrath et al., 2012). In the present study, we examined the temporal sequence between depressive symptoms and perfectionism in children approximately 12 years of age at T1 over three years in order to assess which model (vulnerability, scar, or reciprocal-causality) best explained the relationship between depressive symptoms and perfectionism.

\section{Conceptualization of Perfectionism}

Although there is no standard definition of perfectionism, researchers have described individuals with perfectionism as setting very high, even unattainable, standards for themselves and persistently attempting to meet these (Flett \& Hewitt, 2002). Often perfectionistic behaviours are motivated by fears of failure and disappointing others (Hamachek, 1978). Perfectionists' self-worth is contingent on their performance which they may often criticize (Flett \& Hewitt, 2002). As well, individuals with perfectionism may request others to be perfect (Hewitt \& Flett, 1991b).

In the current study Hewitt and Flett's (1991b) conceptualization of perfectionism was used because it is well-validated and most commonly used in perfectionism research (e.g., Chang and Rand, 2000; Flett, Coulter, Hewitt, \& Nepon, 2011; Flett et al., 1995; Flett, Panico, \& Hewitt, 2011; Stoeber, Otto, \& Dalbert, 2009). Hewitt and Flett posited that perfectionism consists of three dimensions which differ not in the behaviour per se, but in the target (self vs. others) and motivation (socially- vs. self-motivated) of the perfectionistic behaviour. These dimensions are socially prescribed perfectionism (SPP), self-oriented perfectionism (SOP), and others-oriented perfectionism (OOP). 
SPP is the belief that significant others hold excessively high expectations and standards for oneself and the individual feels need to satisfy these high demands (Hewitt \& Flett, 1991b). There may also be a need to appear perfect for others (Hewitt et al., 2003). SOP refers to the tendency to set high standards of performance for oneself and stringently evaluate one's behaviours (Hewitt \& Flett, 1991b). Finally, OOP refers to the belief that others should perform flawlessly. That is, setting unrealistically high expectations and standards for others, evaluating them stringently, and potentially blaming them for their shortcomings (Hewitt \& Flett, 1991b).

Although experiencing high levels on any of these dimensions can be related to psychological maladjustment, SOP and SPP are particularly associated with negative emotional states. OOP is more often associated with interpersonal issues (Chang \& Rand, 2000). Unlike OOP, both SOP and SPP dimensions of perfectionism place the perfectionistic expectations on the individual rather than on others. It is not surprising then that feeling unable to meet one's or other's high expectations and standards are related to feelings of worthlessness and self-criticism (Hewitt \& Flett, 1991b). Because SOP and SPP tend to be more highly associated with psychopathology than OOP (e.g., Chang \& Rand, 2000; Flett, Besser, Davis, \& Hewitt, 2003; Hewitt \& Flett, 1991b), we focused solely on these two dimensions in this study.

\section{Perfectionism and Depression}

In adults, elevated levels of perfectionism have been associated with a wide range of psychopathology including depression and depressive symptoms in a variety of cross-sectional studies using clinical and non-clinical adult populations (Frost, Holt, Mattia, \& Neubauer, 1993; Hewitt et al., 1996; Slaney, Rice, Mobley, Trippi, \& Ashby, 2001). As well, researchers have found that the different dimensions of perfectionism noted by Hewitt and Flett (1991b) tend to differentiate disorders. In general, SPP seems to be more highly associated with depressive 
symptoms and depression (e.g., Cox \& Enns, 2003; Enns \& Cox 2002; Flett et al., 2011; Hewitt et al., 1996), while SOP tends to be more highly correlated with other disorders such as anxiety (e.g., Flett, Greene, \& Hewitt, 2004, Flett, Madorsky, Hewitt, \& Heisel, 2002; Hewitt et al., 2002), or predict depressive symptoms indirectly through interactions with stressors (e.g., achievement-related life stress, Flett et al., 1995; Hewitt et al., 1996). For example, only SPP and not SOP, was found to correlate with depression in depressed outpatients (Enns \& Cox, 1999) and university students (e.g., Flett, Hewitt, Blankstein, \& O'Brien, 1991). Nonetheless, some researchers have argued that both SOP and SPP are directly related to depression. In psychiatric patients diagnosed with mood disorders, both SOP and SPP predicted levels of depression (Hewitt \& Flett, 1991a). Similarly, Hewitt, Flett, Ediger, Norton, and Flynn (1998) found that, in individuals diagnosed with unipolar depression, SOP predicted chronic depression while SPP predicted state depression, suggesting that perfectionism not only contributes to current depression but can also increase the likelihood of experiencing recurrent depression (Hewitt et al., 1998).

There is some evidence that perfectionism is also associated with negative emotionality in children and adolescents. Researchers studying perfectionism and depression cross-sectionally have reported that SPP and SOP are positively associated with depression in populations of nonclinical and clinical children (e.g., Castro et al., 2004; Huggins et al., 2008). Hewitt and colleagues (2002) demonstrated a link between perfectionism and depression in Canadian school-aged students. The authors found that SPP and SOP predicted depressive symptoms (Hewitt et al. 2002), as in adults (Hewitt \& Flett, 1991a).

Despite the existence of evidence for the association of SOP and SPP with depression in children and adolescents, it appears that SPP may be more highly associated with depression 
than SOP, as proposed in the adult literature. In support of this hypothesis, Kenney-Benson and Pomerantz (2005) found that children who had high levels of both SOP and SPP were more likely to have higher levels of depression compared to children with lower SOP and SPP levels. However, SPP correlated more highly than SOP with depression. In fact, once SPP was taken into account, the relationship between SOP and depression was no longer statistically significant. As well, SOP failed to predict depressive diagnostic status in another study (Huggins et al., 2008). Hence, while some authors found support for a link between SOP and depression in both childhood and adulthood, there is more consistent support for a link between SPP and depression in cross-sectional studies. SPP may be especially associated with depression in late childhood and adolescence as this is a period in development when individuals are highly sensitive to being socially accepted and integrated in peer groups (Berndt, 1979; Hewitt, Newton, Flett, \& Callander, 1997).

The issue with the cross-sectional studies reviewed herein is that the directional link between perfectionism and depression cannot be identified. The few (short-term) longitudinal studies existing on perfectionism and depression in children, adolescents, and adulthood reviewed below suggest that there is an association between perfectionism and depression. What is not known however, is whether perfectionism is a risk factor for, an outcome of, or shares a reciprocal relationship with, depression. In this study, we attempted to address this issue by examining three different models that could explain the relationship between depression and perfectionism over time. In the vulnerability model, perfectionism is seen as a risk factor for depression. In the scar model, perfectionism is viewed as a consequence of depression. Finally, the reciprocal-causality model assumes that depression and perfectionism simultaneously influence each other over time. 


\section{Vulnerability Model}

The vulnerability model posits that personality traits, such as SOP and SPP may increase depressive symptoms over time (Bagby, Quilty, \& Ryder, 2008; Sherry et al., 2012). To be a vulnerability factor the personality traits must precede and be statistically associated with the outcome (i.e., depression; Jacobi, Hayward, de Zwaan, Kraemer, \& Agras, 2004).

The vulnerability model is often found or implied in the perfectionism and mental health literature (e.g., Flett et al., 1995; Hawley, Ho, Zuroff, \& Blatt, 2006). For example, in an adult clinical sample, SPP predicted increases in depression over a period of four months (Hewitt et al., 1996). More recently, Sherry and colleagues (2012) have found that "discrepancies", a dimension of perfectionism falling under the same family of perfectionism traits as SPP, predicted changes in depressive symptoms of first year undergraduate students over three time points in a period of four and a half months. They also tested the reverse link where depression predicted changes in perfectionism and did not find support for it (see also Hawley et al., 2006).

Similar observations have been made in studies involving children and adolescents.

O’Connor, Rasmussen, and Hawton (2010) found that SPP predicted depressive symptoms in 14to 16-year-old students over a 6-months period. Changes in maladaptive perfectionism (perfectionism traits associated with SPP) also predicted changes in depressive symptoms one year later in 15- to 16- year-old students (Soenens et al., 2008). Similar results were supported in two other longitudinal studies (Einstein, Lovibond, \& Gaston, 2000; McCreary, Joiner, Schmidt, \& Ialongo, 2004). For the reason that perfectionism studies often conceptualizes the relationship between perfectionism and depression through the vulnerability standpoint, the research design and statistics used may be predetermined to fit with the model (McGrath et al., 2012). That is, while these studies support the model, they have not tested it specifically nor compared it to the 
competing models (scar and reciprocal-causality models), rather most have just assumed that this was the case (with the exception of Sherry et al., 2012 and McGrath et al., 2012). Hence, the competing models have often been overlooked.

\section{Scar Model}

The scar model of depression and perfectionism contends that depressive symptoms may lead to changes in personality. In this case, depressive symptoms come before perfectionism, hence are a risk factor rather than an outcome of perfectionism (Coyne \& Whiffen, 1995; Shahar et al., 2004). Depressive symptoms can affect key areas of functioning, such as the social and psychological domains, and may alter or impair personality-related patterns of behaving, reasoning, interacting, and perceiving (Judd, Schettler, \& Akiskal., 2002; McGrath et al., 2012; Rhode, Lewinsohn, \& Seeley, 1990). Hence, personality traits can be changed as a result of the depressive symptoms (Bagby et al., 2008, Corruble, Duret, Pelissolo, Falissard, \& Guelfi, 2002).

Research on the scar model in the perfectionism and depression literature is rare and yields inconsistent results. Cox and Enns (2003) demonstrated that SPP levels are exacerbated or elevated during major depressive episodes, suggesting that depression can increase perfectionism over time (Zuroff, Blatt, Sanislow, Bondi, \& Pilkonis, 1999). As well, in a study of Finnish undergraduate students elevated depressive symptoms predicted decreases in positive appraisal of personal projects two years later (Salmala-Aro \& Nurmi, 1996). Specifically, depression promoted self-criticism, a notion engrained in perfectionism (Hewitt \& Flett, 1991b). Other researchers have not found evidence to support the scar model (e.g., Rice \& Aldea, 2006; Sherry et al., 2012). To our knowledge, no longitudinal studies investigating this model in children and adolescents exist.

\section{Reciprocal-Causality Model}


According to the reciprocal-causality model, perfectionism and depressive symptoms may be inter-related. Hence, the vulnerability and scar models may not be mutually exclusive (Hawley et al., 2006; McGrath et al., 2012), but rather they may co-occur with changes in SOP and SPP influencing depressive symptoms, and depressive symptoms simultaneously influencing SOP and SPP traits over time. Hence, this model is a bi-directional model incorporating both the scar and the vulnerability models.

Research on this model is equivocal. In a 16-week study of individuals diagnosed with depression undergoing treatment (Hawley et al., 2006) and in a 130-day longitudinal study of undergraduate students (Sherry et al., 2012), no support for a reciprocal relationship was found. However, in other studies, support for the reciprocal-causality model was found. In their 4-week longitudinal study on undergraduate students, McGrath and colleagues (2012) found a reciprocal relationship between depressive symptoms and self-critical perfectionism and perfectionistic striving (dimensions of perfectionism which encompasses SPP and SOP traits, respectively; McGrath et al., 2012; Sherry et al., 2012). That is, perfectionism predicted increases in depression and depression predicted increases in perfectionism over time (McGrath et al., 2012). In children and adolescents, there is only one study investigating this model. Shahar, Blatt, Zuroff, Kuperminc, and Leadbeater (2004) reported that self-criticism predicted depression and vice versa in their 12-months longitudinal study of 11- to 14-year-old children, however these results were true of girls only. The discrepancy between these findings may be due to differences in population and age group studied, duration of the study, and measures used.

In sum, based on the current state of the research on the temporal sequence between perfectionism and depression in childhood, we cannot conclude on whether perfectionism is a risk factor for (vulnerability model), outcome of (scar model), or shares a reciprocal relationship 
(reciprocal-causality model) with depression in childhood and adolescence. Although most studies point to the vulnerability model, the statistical analyses used in these studies may be predetermined to fit with the model and do not test other relationship possibilities.

\section{Present Study}

In the current study, we investigated the temporal relationship between perfectionism (SOP and SPP) and depressive symptoms in school-aged boys and girls across three years. Specifically, we tested the vulnerability, scar, and reciprocal-causality models which contained cross-lagged effects. Such models typically control for both the cross-sectional association between the constructs as well as their stability across time, while examining the cross-lagged effects (Masten \& Cicchetti, 2010). Hence, in examining the three models, our objectives included investigating (1) the concurrent relationship and stability of depressive symptoms and both SOP and SPP and (2) models containing concurrent relations and stability estimates of perfectionism (SOP and SPP) and depressive symptom, as well as potential cross-lagged paths.

Longitudinal studies investigating the perfectionism-depressive symptoms link in childhood are sparse and yield mixed results. One study suggests a reciprocal relation between both factors (Shahar et al., 2004). The others support a vulnerability hypothesis (Einstein et al., 2000; McCreary et al., 2004; O’Connor et al., 2010; Soenens et al., 2008); however, other relationship possibilities were not tested in the later studies. As well, despite the fact that Shahar and colleagues (2004) have tested the reciprocal-causality model, they did not use a perfectionism measure per se, but rather used a scale measuring traits related to perfectionism (i.e., self-criticism). Thus to clarify the issue, we tested all three models using a well-validated measure of perfectionism in children. 
We also examined the role of sex as a moderator because, although studies have not found sex differences in perfectionism per se (e.g, Rice, Leever, Noggle, \& Lapsley, 2007), girls have been repeatedly found to experience more depressive symptoms than boys, particularly as they enter puberty (e.g., Angold, Costello, Erkanli, \& Worthman, 1999; Nolen-Hoeksema \& Girgus, 1994). Generally, researchers studying the perfectionism-depression relationship in children have not investigated (e.g., Flett et al., 2011), or have not found sex differences (Einstein et al., 2000; Hewitt et al., 2002; Huggins et al., 2008; Kenny-Benson \& Pomerantz, 2005; Soenens et al., 2008), with a few exceptions. In McCreary and colleagues' (2004) study on African American children, SPP was predictive of depressive symptoms one year later in boys only. Shahar and colleagues (2004) also showed that the relationship between perfectionism related traits and depression was differentiated by the sex of the children; self-criticism and depression shared a reciprocal association in girls, but not boys.

\section{Hypotheses}

Based on previous longitudinal investigations in children and adolescents which found more support for a relationship between SPP, than SOP, and depression (e.g., Einstein et al. 2002; O'Connor et al., 2010; Soenens et al., 2008), potentially due to their strong desire to be socially accepted and integrated within peer groups (Berndt, 1979; Hewitt, et al., 1997), it was hypothesized that SPP, rather than SOP, would share a longitudinal relationship with depressive symptoms. As well, based on the only other longitudinal study testing all three models in children and adolescents (i.e., Shahar et al., 2004), it was hypothesized that the reciprocalcausality model would be the best fit in this population. Issues with developing and maintaining a stable positive self-esteem can lead to experiencing depressive symptoms (Orth, Robins, \& Roberts, 2008), perhaps particularly if these issues arise as a consequence of feeling unable to 
meet others' (SPP) expectations (O’Connor et al., 2010). Perfectionism contains core attributes (i.e., negative self-evaluation and -criticism) and preoccupations (i.e., meeting unrealistic expectations) that individuals at risk for depressive symptoms may hold (Hewitt \& Flett, 1991b). Hence, perfectionism may be a premorbid personality trait of individuals vulnerable to depressive symptoms. Drawing on this research, we expected that perfectionism would be both a precursor and contributor of depressive symptoms.

We also expected that, simultaneously, perfectionism would be a complication of depressive symptoms. Experiencing depressed mood may increase individuals' accessibility to negative schemas (Persons \& Miranda, 1992; Segal \& Ingram 1994; Teasdale, 1983), similar to those associated with perfectionistic thinking (needing to meet unrealistic standards). As well, the impairments in the social domain associated with experiencing depressive symptoms may result in experiencing perfectionistic traits. For example, the criticism and rejection frequently accompanying depressive symptoms (Coyne, 1976; Hammen, 1991) can lead to perceiving that others are expecting perfection.

Finally, because sex differences have been repeatedly found in depressive symptoms (e.g., Angold et al., 1999; Nolen-Hoeksema \& Girgus, 1994) we tested for sex differences in the perfectionism-depression relationship. However, because most studies assessing the perfectionism-depression relationship in children and adolescents did not find any sex differences (e.g., Einstein et al., 2000; Soenens et al., 2008), sex was not expected to moderate the perfectionism-depression link.

\section{Methodology}

\section{Participants}


In the current study, data collected as a part of a larger on-going study (McMaster Teen Study) investigating mental health and peer relationships in children and adolescents were used. In total, data from 653 students where approximately half were girls $(n=286,53.6 \%)$ was used for the current study. Their mean age was 12.18 years $(S D=0.41)$ in grade 6 at Time $1(\mathrm{~T} 1)$. The majority of students self-identified as European-Canadian (64.2\%). A smaller number were Middle-Eastern-Canadian (1.7\%), African/West-Indian-Canadian (2.9\%), Asian-Canadian (1.7\%), South-Asian-Canadian (2.8\%), Native-Canadian (1.1\%), South/Latin AmericanCanadian (.9\%), and Other (3.4\%). Some did not did not know $(11.4 \%)$ their ethnicity or did not answer $(10 \%)$ the question.

Of the 653 participants included in the current study, 572 participants remained in the study until Grade 8 (548 participated and 24 others expressed interest in participating in the study in future years but could not take part that year) and 19 students dropped out. In Grade 7 , 11 participants dropped out. Dropouts and all others (e.g., those who were unreachable) were considered "non-participants". Non-participants and those who remained in the study did not significantly differ on prior reports of depressive symptoms, SOP, and SPP ( $t \mathrm{~s}>.05)$.

\section{Measures}

As part of the larger study, children completed a battery of self-report questionnaires on mental health and personality, amongst other measures. In this study, only questionnaires addressing depressive symptoms and perfectionism only were used.

Depression. The Behaviour Assessment System for Children Second Edition (BASC-2; Reynolds \& Kamphaus, 2004) Self-Report of Personality (SRP) child version was administered to the students in Grade 6 and adolescent version in Grades 7 and 8. Scores on the depression subscale containing 13 items measuring sadness, hopelessness, and loneliness (e.g., “I just don’t 
care anymore." and "No one understands me") only were used for the purposes of this study. There was approximately equal numbers of true or false and 4-point Likert scale items $($ Never $=$ 0 , Sometimes $=1$, Often $=2$, Almost always $=3$ ). Overall depressive symptoms were calculated by summing the scores of each item. Higher scores on this scale indicated greater depressive symptoms.

The internal consistency for the BASC-2 depression scale was high in our sample with an alpha coefficient of .88 in Grades 6 and 8 and .87 in Grade 7. The BASC-2 has also shown moderate concurrent validity with other depression scales $(r=.72$ with the withdrawn/ depressed subscale of the Achenbach System of Empirically Based Assessment Youth Self-Report; Reynolds \& Kamphaus, 2004).

Perfectionism. The Child-Adolescent Perfectionism Scale (CAPS; Flett, Hewitt, Boucher, Davidson, \& Munro, 1997), a 22-item self-report scale with two subscales measuring SPP (10 items; e.g., 'My family expects me to be perfect') and SOP (12-items; e.g., 'I want to be the best at everything I do') was administered in Grades 7 and 8. Children and adolescents rated the items on a 5-point Likert scale where 1 was 'not at all true of me' and 5 was 'very true of me'. Higher scores on each sale suggested greater perfectionism levels.

The CAPS is a reliable measure used extensively in perfectionism research in nonclinical populations of children and adolescents ages 8 to 18 years (e.g., Castro et al., 2004; Flett et al., 1997). Its subscales had good internal consistency in our sample with an alpha of .84 in Grade 7 and .89 in Grade 8 for SOP and .88 in Grade 7 and .90 in Grade 8 for SPP. As well, adequate evidence of concurrent validity with other measures of perfectionism has also been established ( $r$ $=.76$ for the SOP factor and $r=.39$ for the SPP factor with the Perfectionistic Self Presentation Scale; Castro et al., 2004; Flett et al., 1997). 


\section{Procedure}

The study was granted approval by the University of Ottawa and McMaster University Research Ethics Boards. Prior to each wave of data collection (conducted in the spring of each year), parents were requested to provide consent and students were asked to provide assent after being informed that their response to the questionnaires remained confidential with one exception: those with high depression scores would be contacted the principle researcher for referral to a heath care professional if needed. The students had the option (identified on the parental consent forms) to fill out the survey by paper or online at their convenience. Depending on their choice, a paper copy of the survey was mailed along with a prepaid and addressed return envelope or a link to Survey Monkey was emailed to the students. Students were compensated with a gift card ( $\$ 10$ in grade 6 and 7 and $\$ 20$ in grade 8$)$.

\section{Data Analyses}

To investigate the perfectionism-depressive symptoms link, structural equation modeling in AMOS 20.0.0 (Amos Development Corporation, 2011) was used. Similar to Shahar and colleagues (2004) we estimated and compared the vulnerability, scar, and reciprocal-causality models (see Figure 1) in school-aged students to test the relationship between (1) SOP and depressive symptoms and (2) SPP and depressive symptoms across Grades 6 to 8.

The vulnerability model contained cross-lagged paths from both SOP and SPP in Grade 7 to depressive symptoms in Grade 8. The scar model contained crossed-lagged paths from depressive symptoms in Grades 6 and 7 to both SOP and SPP in Grades 7 and 8. The reciprocalcausality model contained cross-lagged paths from depressive symptoms to both SOP and SPP as well as cross-lagged paths from both SOP and SPP to depressive symptoms from Grades 6 to 8 . To stringently test these models, we included within-time correlations to control and adjust for 
the concurrent relationships between variables, as well as autoregressive paths (stability paths) between repeated measures to control for prior levels of depressive symptoms, SOP, and SPP (Masten \& Cicchetti, 2010). We also controlled for the potential cross-lagged effects between SOP and SPP (i.e., controlled for their interrelations across time).

To investigate whether sex moderated the perfectionism-depression link, we ran a multigroup analysis on the best fitting model. We first tested a sex specific model in which all parameters were freely estimated across sex, and a second, sex invariant model where crosslagged paths between depressive symptoms and both SOP and SPP were constrained to equality across sex. Finally, we tested a trimmed model, where all non-significant paths of the best fitting model were removed for parsimonious reasons (Byrne, 2001).

The comparative fit index (CFI) and the root mean square error of approximation (RMSEA) were used to indicate goodness-of-fit. CFI values above .95 indicated close fit (Hu \& Bentler, 1999). RMSEA values between .06 and .08 indicated acceptable fit and values below .06 indicated close fit (Browne \& Cudeck, 1993). Although the $\chi^{2}$ test of significance is reported, it was not used as an indicator of fit because it has been shown to be sensitive to large samples (Kline, 2005). To compare nested models we used the chi-squared and CFI difference tests. If the $\Delta \chi^{2}$ had a $p<.05$ and $\Delta$ CFI $>.01$ the models were statistically significantly different (Cheung \& Rensvold, 2002). If the models were not statistically significantly different, the most parsimonious model (i.e., the model with the fewest parameters) was preferred (Byrne, 2001). To compare non-nested models we used the Akaike information criterion (AIC) as a measure of fit. The model with the lower AIC value was considered to fit best (Akaike, 1974, 1987).

\section{Results}

\section{Missing Data}


Participants with data at one time point or more on the perfectionism or depression scales were used in the study. Overall, $17.13 \%$ of data were missing across all time points. A Little's Missing Completely at Random test (Little, 1988) indicated that these data were missing completely

at $\operatorname{random} \chi^{2}(111, N=653)=113.98, p>.05$. To handle missing data for the descriptives and correlations, the listwise deletion method was applied, while the full information maximum likelihood (FIML) estimation method was used to handle missing data for the path analysis. FIML rather than the listwise deletion or mean imputation methods was applied to maximize the amount of data that can be used and yield less biased estimates (Acock, 2005).

\section{Descriptive Statistics}

Bivariate correlations are presented in Table 1. Cross-sectionally, correlations between depressive symptoms and SOP and SPP in Grade 7, as well as SPP (but not SOP) in Grade 8, were positive and statistically significant. Also, SOP and SPP positively correlated with each other in Grades 7 and 8. Longitudinally, depression was positively and significantly correlated with SPP but not SOP, suggesting merit in investigating the temporal relationship between depression and perfectionism, particularly SPP, in our sample.

Means, standard deviations, and sex difference tests for depression, SOP, and SPP at each grade are presented in Table 2. Post-hoc mean comparisons and Cohen's $d$ estimates of effect size (Cohen, 1988) revealed sex differences in mean depression, but not perfectionism $(p s>.05)$, levels. That is, although no statistically significant Time X Sex interactions emerged for depressive symptoms and perfectionism, girls experienced higher levels of depressive symptoms than boys in the later adolescent years, in Grades $7(d=.34)$ and $8(d=.35)$.

\section{The Perfectionism-Depressive Symptoms Link}


We estimated the fit of each model presented in Figure 1. The fit statistics of each model are presented in Table 3 (see Models 1 to 3). The fit of the first model, the vulnerability model, was acceptable, $\chi^{2}(7)=39.397, p<.01, \mathrm{CFI}=.973, \mathrm{RMSEA}=.084(90 \% \mathrm{CI}=.060-.111)$. In this model, depressive symptoms $(b=.57, \beta=.62$ for Grades 6 to 7 and $b=.52, \beta=.51$ for Grades 7 to $8, p$ s $<.01)$, SOP $(b=.74, \beta=.67$ for Grades 7 to $8, p<.01)$, and SPP $(b=.60, \beta=$ .56 for Grades 7 to $8, p<.01$ ) were stable across time. Perfectionism did not significantly predict depressive symptoms and both SOP and SPP were not interrelated across time ( $p$ s > .05).

We compared the fit of the vulnerability model to the fit of the second model, the scar model. The scar model fit our data well, $\chi^{2}(5)=11.320, p<.05, \mathrm{CFI}=.995, \mathrm{RMSEA}=.044$ $(90 \% \mathrm{CI}=.006-.079)$ and fit our data better than the vulnerability model as shown by its lower AIC value (vulnerability model, AIC = 95.397; scar model, AIC = 71.320). In the model, depressive symptoms $(b=.60, \beta=.64$ for Grades 6 to 7 and $b=.55, \beta=.54$ for Grades 7 to $8, p$ s $<.01), \operatorname{SOP}(b=.75, \beta=.68$ for Grades 7 to $8, p<.01)$, and SPP $(b=.55, \beta=.52$ for Grades 7 to $8, p<.01)$ were stable over time. SOP in Grade 7 predicted SPP in Grade $8(b=.10, \beta=.10, p$ $<.05)$, but SPP did not predict SOP from Grade 7 to $8(p>.05)$. As well, depressive symptoms predicted SPP (Grade 6 to $7 b=.28, \beta=.18, p<.01$, and Grade 7 to $8, b=.14, \beta=.08, p<.05$ ), but not $\mathrm{SOP}(p \mathrm{~s}>.05)$.

We then estimated the last model, the reciprocal-causality model and compared it to the vulnerability and scar models. The reciprocal-causality model also fit our data well, $\chi^{2}(3)=$ $7.825, p=.05, \mathrm{CFI}=.996, \mathrm{RMSEA}=.050(90 \% \mathrm{CI}=.001-.094)$ and fit better than the vulnerability model, $\Delta \chi^{2}(4)=31.572, p<.01, \Delta \mathrm{CFI}=.023$, but did not differ in fit from the scar model, $\Delta \chi^{2}(2)=3.495, p>.05, \Delta \mathrm{CFI}=.001$. As in the previous models, depressive symptoms $(b$ $=.60, \beta=.64$ for Grades 6 to 7 and $b=.54, \beta=.53$ for Grades 7 to $8, p$ s $<.01), \operatorname{SOP}(b=.74, \beta$ 
$=.67$ for Grades 7 to $8, p<.01)$, and SPP $(b=.57, \beta=.54$ for Grades 7 to $8, p<.01)$ were stable across time. SOP and SPP were not interrelated across time ( $p$ s $>.05)$. Also, SPP (but not SOP, $p$ s > .05) predicted depressive symptoms (scar paths) from Grades 6 to 7 ( $b=.28, \beta=.18, p<$ $.01)$ and 7 to $8(b=.14, \beta=.08, p<.05)$. However, perfectionism did not predict depressive symptoms (vulnerability paths; $p s>.05$ ). Therefore, because the scar model is more parsimonious (Byrne, 2001) than the reciprocal-causality model, and the only significant paths in the reciprocal-causality model were the scar paths, the scar model was chosen as the best fitting model .

Multigroup model. The fit and sex difference test statistics are presented in Table 3 (see Models 4 and 5). The sex specific model fit the data well, $\chi^{2}(10)=17.595, p>.05, \mathrm{CFI}=.994$, RMSEA $=.034(90 \% \mathrm{CI}=.000-.060)$. It was then compared to a sex invariant model where cross-lagged paths from depressive symptoms in Grades 6 and 7 to both SOP and SPP in Grades 7 and 8 were held equal across sex. The sex invariant model also fit the data well, $\chi^{2}(14)=$ $21.396, p>.05, \mathrm{CFI}=.994, \mathrm{RMSEA}=.010(90 \% \mathrm{CI}=.000-.051)$. Allowing for sex differences did not improve fit to the data, $\Delta \chi^{2}(3)=3.801, p>.05, \Delta \mathrm{CFI}=.000$, suggesting that the longitudinal paths between depression and both SPP and SOP in the scar model were sex invariant.

Trimmed model. Because there were no sex differences, we returned to the single group scar model and re-estimated it with one non-significant path removed a time, examining the fit each time a path was removed. The model fit did not change at any point during trimming. Also, the paths' significance levels remained similar throughout trimming. The final trimmed scar model fit the data well, $\chi^{2}(8)=12.890, p>.05, \mathrm{CFI}=.996, \mathrm{RMSEA}=.031(90 \% \mathrm{CI}=.000-$ .060), (Model 6, Table 3), and did not significantly differ from the untrimmed scar model, $\Delta \chi^{2}(3)$ 
$=1.570, p>.05$ and $\Delta \mathrm{CFI}=.001$. The trimmed scar model represented the most parsimonious of the models tested and, as such, was chosen as the final model (see Figure 2 for standardized path coefficients).

In our final model (trimmed scar model), depressive symptoms, SOP, and SPP were stable; autoregressive paths were statistically significant for depressive symptoms $(b=.61, \beta=$ .64 for Grades 6 to 7 and $b=.55, \beta=.54$ for Grades 7 to $8, p s<.01)$, SOP $(b=.73, \beta=.66$ for Grades 7 to $8, p<.01)$, and SPP $(b=.57, \beta=.53$ for Grades 7 to $8, p<.01)$. The autoregressive paths for depressive symptoms from Grades 6 to 7 and 7 to 8 were not significantly different from each other $(p s>.05)$. SOP in Grade 7 predicted SPP in Grade $8(b=.09, \beta=.09, p<.05)$ As well, depressive symptoms predicted SPP (Grade 6 to $7, b=.30, \beta=.19, p<.01$, and Grade 7 to $8, b=.16, \beta=.09, p<.05)$. The cross-lagged paths from depressive symptoms to SPP from grades 6 to 7 and 7 to 8 were not significantly different from each other ( $p s>.05$ ).

\section{Discussion}

In the present study, a longitudinal investigation of the perfectionism-depression connection in childhood over three years was conducted using cross-lagged analyses in order to investigate whether perfectionism (SOP and SPP) is a risk factor for (vulnerability model), an outcome of (scar model), or shares a reciprocal relationship (reciprocal-causality model) with depressive symptoms. Cross-lagged analyses allow capturing the interrelation across time between key areas of development. They are qualified by controlling for cross-sectional correlations and stability over time when testing cross-lagged effects (Masten \& Cicchetti, 2010). We begin our discussion by briefly elucidating the cross-sectional associations between SOP and SPP, as well as between both SOP and SPP and depressive symptoms followed by a discussion on the stability and longitudinal associations of the study variables. 


\section{Cross-Sectional Associations}

As has been shown in other published studies, SOP was highly and positively correlated with SPP within each assessment period (i.e., in Grades 7 and 8). The magnitude of the association was also similar to the magnitude previously observed by researchers (e.g., Huggins et al., 2008). Further, consistent with most studies on perfectionism and depression, depressive symptoms shared a stronger concurrent relationship with SPP than SOP (Huggins et al., 2008;

O’Connor et al., 2010; Kenney-Benson \& Pomerantz, 2005; McCreary et al., 2004). Although both SOP and SPP were concurrently associated with depressive symptoms in Grade 7, the correlations between SOP and depressive symptoms was smaller than SPP $(r=.11$ for SOP and $r$ $=.29$ for SPP). As well, SPP, but not SOP, correlated with depressive symptoms in Grade 8 .

In sum, as observed in previous cross-sectional studies, our findings suggest that the two dimensions of perfectionism under investigation, namely SOP and SPP, were highly and positively correlated. As well, depressive symptoms were more consistently associated with SPP than SOP.

\section{Stability}

Similar to previous studies assessing the stability of depression (see Tram \& Cole, 2006 for a review), we found that depressive symptoms were stable across three years. We also extended the current state of the literature on perfectionism in children and adolescents by being one of the first studies to provide stability estimates across two years from children in Grades 7 and 8, showing that both SOP and SPP were stable across time.

\section{Perfectionism-Depressive Symptoms Link}

As hypothesized, we found that depressive symptoms shared a longitudinal relationship with SPP rather than SOP; although depressive symptoms were associated with concurrent SOP 
and SPP levels, they predicted change over time in SPP levels only. That is, depressive symptoms positively predicted SPP one year later, from Grades 6 to 7 and 7 to 8 . In contrast, depressive symptoms did not predict SOP in Grades 6 to 8. It may be that, just as in adults, SOP is associated with other symptoms, for example, anxiety (Flett et al., 2004, Flett et al., 2002; Hewitt et al., 2002), or predict depression indirectly through interactions with stressors (Flett et al., 1995; Hewitt et al., 1996). Because SPP is a perfectionism trait that is associated with wanting to meet others' expectations and appear perfect, it may be particularly linked with depression in late childhood and adolescence, as it a period in development where individuals strongly desire to be socially accepted and included in peer groups (Berndt, 1979; Hewitt et al., 2003; Hewitt et al., 1997).

Taken together, our analyses showed that the scar, rather than the hypothesized reciprocal-causality model posited by Shahar and colleagues (2004), represented our data best. Although, the scar and reciprocal-causality model did not differ in terms of fit, the scar model was chosen based on parsimony and because the only significant longitudinal paths in the reciprocal-causality model were the scar paths indicating that changes in depressive symptoms lead to changes in perfectionism. Specifically, in our samples, increases in depressive symptoms lead to increases in perfectionism, primarily SPP, after controlling for the within-time correlations between the variables, the across-time stability, as well as the potential effects of the interrelation between SOP and SPP over time. Similar to other studies investigating the depression-perfectionism association in childhood (e.g., Einstein et al., 2000; Soenens et al., 2008) and consistent with our hypotheses, we also found that sex did not moderate the relationship, despite mean-level differences in depressive symptoms. The discrepancy between Shahar and colleagues' and our results may be due to the difference in measures used. We used a 
scale specifically measuring perfectionism rather than a scale measuring traits related to perfectionism (i.e., self-criticism) and a different depression inventory adapted for children and adolescents, allowing for a more precise and reliable investigation of the perfectionismdepression link.

The mechanisms by which depressive symptoms might increase perfectionism are still unclear although various hypotheses can be contemplated. First, depressive symptoms may allow for easier access to individuals' negative schemas and dysfunctional attitudes (Persons \& Miranda, 1992; Segal \& Ingram 1994; Teasdale, 1983) such as those present in SPP traits (e.g., others request oneself to perform flawlessly). That is, the motivational issues, behaviour avoidance, negative cognitions about the self and others as well as rumination associated with depressive symptoms (Beck et al., 1979) can exacerbate or cause SPP traits. Depressive symptoms may intensify key concerns for individuals with SPP, for example, by increasing the perception that others consider their mistakes as veritable failures creating opportunities for selfcriticism. Second, because youth with depressive symptoms may experience interpersonal deficits (Rudolph, Flynn, \& Abaied, 2008), they may seek or elicit negative feedback from others (Joiner, Katz, \& Lew, 1997; Joiner, 1994) allowing for negative schemas associated with SPP to develop. For example, the criticism and rejections (forms of negative feedback) individuals with depressive symptoms may experience (Coyne, 1976; Hammen, 1991) can create the perception that others are expecting perfection from them.

Why, then, did perfectionism not increase depressive symptoms (vulnerability model)? Because of the dearth in empirical investigation of the three models in children and adolescents, a definite explanation for this unexpected finding reported here awaits future studies. However, it is possible that, at a young age, perfectionism is a complication of depression, and in the later 
stages of development, both constructs share a different association. For example, in adulthood, depression may be a result of perfectionistic traits (Sherry et al., 2012), or both depressive symptoms and perfectionism may simultaneously affect each other (McGrath et al., 2012). In other words, it may be that the vicious cycle between perfectionism and depressive symptoms begins with depressive symptoms promoting perfectionistic personality traits.

Children and adolescents are often exposed to messages that they must attain high standards of performance by their mentors (e.g., needing to obtain high grades or winning soccer games; Damian, Stoeber, Negru, \& Baban, 2013; Yamamoto \& Holloway, 2010). Such messages may be especially internalized by children and adolescents with depressive symptoms. They may believe that if they adopt such perfectionistic behaviours and cognitions, their self-worth may increase, alleviating their depressive symptoms (i.e., perfectionism is used as a coping mechanism). Such behaviour may be reinforced if they receive positive feedback for their perfectionistic behaviour. Thus perfectionism may be a personality trait learned and internalized especially by youth vulnerable to depressive symptoms in late childhood and adolescence, a period where self-consciousness and attentiveness to social standards amplifies.

\section{Limitations}

A number of limitations warrant discussion. First, the generalizability of the study is limited to students between the ages of 12 to 14 . Second, although we attempted to identify the directionality of the relationship between perfectionism and depressive symptoms, there may be other explanations for the relationship; a third variable, for example an authoritarian, harsh, and controlling parenting style may cause depressive symptoms and perfectionismin children (Enns, Cox, \& Clara, 2002; see Flett, Hewitt, Oliver, \& Macdonald, 2002 for a review). As well, because we used self-report measures, the participants' responses to questionnaires may be 
subject to biases. For instance, because perfectionism can be viewed positively, encouraged, and often associated with excellence by society, the students may have responded to this questionnaire in a manner that would represent themselves more perfectionistic than they actually are in order to appear more desirable (social desirability bias; see Edwards, 1953). Finally, the results of the current study should be interpreted with caution as some authors have suggested that the perfectionism measure we used (CAPS) is better represented by a three (SOPStriving, SOP-Critical, SPP) rather than two factor model (McCreary et al., 2004; O’Connor et al., 2009). We decided to follow the field's convention and use the CAPS as a two factor model so that our results can easily be compared to results from other studies.

\section{Future Directions}

As the current study is the first longitudinal attempt at investigating the interrelation between perfectionism and depression in childhood and adolescence, researchers are encouraged to replicate it. It may be helpful to utilise various measures of perfectionism (i.e., Multidimensional Perfectionism Scale; Hewitt \& Flett, 1991b) validated in children and adolescents as using different measures may present different results. As well, using growth curve modeling may be advantageous. That way, investigating whether different trajectories of perfectionism can be predicted from individuals high compared to low on depression will be possible. We encourage researchers studying the temporal link between perfectionism and depressive symptoms to consider controlling for the cross-lagged effects between SOP and SPP as done in our study, because the significant longitudinal relationship between SOP and SPP that may arise in future studies (as did in ours - SOP predicted SPP one year later) may blur the investigated temporal relationship between perfectionism and depressive symptoms. Finally, it may also be important to test the relationship over many years, throughout adolescence and 
adulthood, to obtain a more complete understanding of the interrelation between perfectionism and depression throughout the lifespan, especially as different patterns have been demonstrated in adulthood (e.g., McGrath et al., 2012).

\section{Clinical Implications and Conclusion}

Our study yielded evidence that depressive symptoms increase perfectionism, particularly, SPP traits, but perfectionism does not affect depressive symptoms. That is, experiencing depressive symptoms may cause increases in the perception that others request one's performance to be perfect and free of mistakes and the need to comply with these irrational perceptions, while the opposite may not be true, at least in children and adolescents. For clinicians, this is notable as it can inform them that clients with SPP traits may believe that the clinician is expecting them to be perfect. Thus they may feel pressure to recover quickly and avoid disclosing all the information related to their depression and difficulties in order to avoid appearing less than perfect. Addressing this issue early in therapy may be beneficial so as to avoid treatment complications.

Understanding the longitudinal relationship between perfectionism and depression in childhood is important as it can guide research, assessment, and therapy by allowing for more accurate and earlier diagnosis, as well as improving treatment, yet is scarce especially in childhood and adolescence. Our three year longitudinal study is the first to investigate the three models of the perfectionism-depressive symptoms link in children and adolescents using a large sample, and suggests that, contrary to what is widely implied, depression leads to perfectionism. Depressive symptoms may exacerbate the perception that others are setting high behavioural standards on oneself and the need to satisfy these. 


\section{References}

Acock, A. C. (2005). Working with missing values. Journal of Marriage and Family, 67, 10121028. doi:10.1111/j.1741-3737.2005.00191.x

Akaike, H. (1974). A new look at the statistical model identification. IEEE Transactions on Automatic Control, 19, 716-723.

Akaike, H. (1987). Factor analysis and AIC. Psychometrika, 52, 317-332. doi:10.1007/ BF02294359

Angold, A., Costello, E. J., Erkanli, A., \& Worthman, C. M. (1999). Pubertal changes in hormone levels and depression in girls. Psychological Medicine, 29, 1043-1053. doi: $10.1017 / \mathrm{S} 0033291799008946$

Bagby, R. M., Quilty, L. C., \& Ryder, A. (2008). Personality and depression. Canadian Journal of Psychiatry, 53, 14-25.

Beck, A. T., Rush, A. J., Shawv, B. F., \& Emery, G. (1979). Cognitive therapy for depression. New York, NY: Guilford Press.

Berndt, T. J. (1979). Developmental changes in conformity to peers and parents. Developmental Psychology, 15, 606-616.

Browne, M. W., \& Cudeck, R. (1993). Alternative ways of assessing model fit. In K. A. Bollen \& J. S. Long (Eds.), Testing structural equation models. (pp. 136-162). Thousand Oaks, CA: Sage.

Byrne, B. N. (2001). Structural equation modeling with AMOS: Basic concepts, applications, and programming. Mahwah, NJ: Lawrence Erlbaum \& Associates.

Castro, J., Gila, A., Gual, P., Lahortiga, F., Saura, B., \& Toro, J. (2004). Perfectionism 
dimensions in children and adolescents with anorexia nervosa. Journal of Adolescent Health, 35, 392-398. doi:10.1016/j.jadohealth.2003.11.094

Chang, E. C., \& Rand, K. L. (2000). Perfectionism as a predictor of subsequent adjustment: Evidence for a specific diathesis-stress mechanism among college students. Journal of Counseling Psychology, 47, 129-137. doi:10.1037/0022-0167.47.1.129

Cheung, G., \& Rensvold, R. (2002). Evaluating goodness-of-fit indices for testing measurement invariance. Structural Equation Modeling, 9, 233-255. doi:10.1207/S15328007SEM09 $02 \_5$

Cohen, J. (1988). Statistical power analysis for the behavioral sciences (2nd ed.). Hillsdale, NJ: Erlbaum.

Corruble, E., Duret, C., Pelissolo, A., Falissard, B., Guelfi, J. D. (2002). Early and delayed personality changes associated with depression recovery? A one-year follow up study. Psychiatry Research, 109, 17-25. doi:10.1016/S0165-1781(01)00366-3

Coyne, J. C. (1976). Depression and the response of others. Journal of Abnormal Psychology, 85, 186-193. doi:10.1037/0021-843X.85.2.186

Coyne, J. C., \& Whiffen, V. E. (1995). Issues in personality as diathesis for depression: The case of sociotropy-dependency and autonomy-self-criticism. Psychological Bulletin, 118, 358378. doi:10.1037/0033-2909.118.3.358

Cox, B. J., \& Enns, M. W. (2003). Relative stability of dimensions of perfectionism in depression. Canadian Journal of Behavioural Science/Revue canadienne des sciences du comportement, 35, 124-132. doi:10.1037/h0087194

Damian, L. E., Stoeber, J., Negru, O., \& Baban, A. (2013). On the development of 
perfectionism in adolescence: Perceived parental expectations predict longitudinal increases in socially prescribed perfectionism. Personality and Individual Differences, 6, 688-693. doi:10.1016/j.paid.2013.05.021

Edwards, A. L. (1953). The relationship between the judged desirability of a trait and the probability that it will be endorsed. Journal of Applied Psychology, 37, 90-93.

Einstein, D. A., Lovibond, P. F., \& Gaston, J. E. (2000). Relationship between perfectionism and emotional symptoms in an adolescent sample. Australian Journal of Psychology, 52, 8993.

Enns, M. W., \& Cox, B. J. (1999). Perfectionism and depression symptom severity in major depressive disorder. Behaviour Research and Therapy, 37, 783-794. doi:10.1016/S00057967(98)00188-0

Enns, M. W., \& Cox, B. J. (2002). The nature and assessment of perfectionism: A critical analysis. In G. Flett \& P. Hewitt (Eds.), Perfectionism: Theory, research, and treatment, (pp. 33-62). Washington, DC: American Psychological Association.

Enns, M. W., Cox, B. J., \& Clara, I. (2002). Adaptive and maladaptive perfectionism: Developmental origins and association with depression proneness. Personality and Individual Differences, 33, 921-935. doi:10.1016/S0191-8869(01)00202-1

Feldman, J. M, Ortega, A. N., McQuaid, E. L., \& Canino, G. (2006). Comorbidity between asthma attacks and internalizing disorders among Puerto Rican children at one-year follow-up. Psychosomatics 47, 333-339. doi:10.1176/appi.psy.47.4.333

Flett, G. L., Besser, A., Davis, R. A., \& Hewitt, P. L. (2003). Dimensions of perfectionism, unconditional self-acceptance, and depression. Journal of Rational-Emotive and Cognitive Behavior Therapy, 21, 119-138. doi:10.1023/A:1025051431957 
Flett, G. L., Coulter, L. M., Hewitt, P. L., \& Nepon, T. (2011). Perfectionism, rumination, worry, and depressive symptoms in early adolescents. Canadian Journal of School Psychology, 26, 159-176. doi:10.1177/0829573511422039

Flett, G. L., Greene, A., \& Hewitt, P. L. (2004). Dimensions of perfectionism and anxiety sensitivity. Journal of Rational-Emotive \& Cognitive-Behavior Therapy, 22, 39-57. doi:10.1023/B:JORE.0000011576.18538.8e

Flett, G. L., \& Hewitt, P. L. (2002). Perfectionism: Theory, research, and treatment. Washington, DC: American Psychological Association.

Flett, G. L., Hewitt, P. L., Blankstein, K. R., \& Mosher, S. W. (1995). Perfectionism, life events, and depressive symptoms: A test of a diathesis-stress model. Current Psychology, 14, 112-137. doi:10.1007/BF02686885

Flett, G. L., Hewitt, P. L., Blankstein, K., \& O'Brien, S. (1991). Perfectionism and learned resourcefulness in depression and self-esteem. Personality and Individual Differences, 12, 61-68. doi:10.1016/0191-8869(91)90132-U

Flett, G. L., Hewitt, P. L., Boucher, D. J., Davidson, L. A., \& Munro, Y. (1997). The ChildAdolescent Perfectionism Scale: Development, validation and association with adjustment. Unpublished manuscript, York University, Toronto, Ontario, Canada.

Flett, G. L., Hewitt, P. L., Oliver, J. M., \& Macdonald, S. (2002). Perfectionism in children and their parents: A developmental analysis. In G. L. Flett \& P. L. Hewitt (Eds.), Perfectionism: Theory, research, and treatment (pp. 89-132). Washington, DC: American Psychological Association.

Flett, G. L., Madorsky, D., Hewitt, P. L., \& Heisel, M. J. (2002). Perfectionism cognitions, 
rumination, and psychological distress. Journal of Rational-Emotive \& CognitiveBehavior Therapy, 20, 33-47. doi:10.1023/A:1015128904007

Flett, G. L., Panico, T., \& Hewitt, P. L. (2011). Perfectionism, type A behavior, and selfefficacy in depression and health symptoms among adolescents. Current Psychology, 30, 105-116. doi:10.1007/s12144-011-9103-4

Fröjd, S. A., Nissinen, E. S., Pelkonen, M. U., Marttunen, M. J., Koivisto, A. M., \& KaltialaHeino, R. (2008). Depression and school performance in middle adolescent boys and girls. Journal of adolescence, 31, 485-498. doi:10.1016/j.adolescence.2007.08.006

Frost, R. O., Heimberg, R. G., Holt, C. S., Mattia, J.I., \& Neubauer, A. L. (1993). A comparison of two measures of perfection. Personality and Individual Differences, 14, 119-126. doi: $10.1016 / 0191-8869(93) 90181-2$

Hamacheck, D. E. (1978). Psychodynamics of normal and neurotic perfectionism. Psychology: A Journal of Human Behavior, 15, 27-33.

Hammen, C. (1991). The generation of stress in the course of unipolar depression. Journal of Abnormal Psychology, 100, 555-561. doi:10.1037/0021-843X.100.4.555

Hawley, L. L., Ho, M. H. R., Zuroff, D. C., \& Blatt, S. J. (2006). The relationship of perfectionism, depression, and therapeutic alliance during treatment for depression: Latent difference score analysis. Journal of Consulting and Clinical Psychology, 74, 930942. doi:10.1037/0022-006X.74.5.930

Hewitt, P. L., Caelian, C. F., Flett, G. L., Sherry, S. B., Collins, L., \& Flynn, C. A. (2002). Perfectionism in children: Associations with depression, anxiety, and anger. Personality and Individual Differences, 32, 1049-1061. doi:10.1016/S0191-8869(01)00109-X

Hewitt, P. L., \& Flett, G. L. (1991a). Dimensions of perfectionism in unipolar depression. 
Journal of abnormal psychology, 100, 98-101. doi:10.1037/0021-843X.100.1.98

Hewitt, P. L., \& Flett, G. L. (1991b). Perfectionism in the self and social contexts: conceptualization, assessment, and association with psychopathology. Journal of Personality and Social Psychology, 60, 456-470. doi:10.1037/0022-3514.60.3.456

Hewitt, P. L., Flett, G. L., \& Ediger, E. (1996). Perfectionism and depression: Longitudinal assessment of a specific vulnerability hypothesis. Journal of Abnormal Psychology, 105, 276-280. doi:10.1037/0021-843X.105.2.276

Hewitt, P. L., Flett, G. L., Ediger, E., Norton, G. R., \& Flynn, C. A. (1998). Perfectionism in chronic and state symptoms of depression. Canadian Journal of Behavioural Science/Revue canadienne des sciences du comportement, 30, 234-242. doi:10.1037/ h0087066

Hewitt, P. L., Flett, G. L., Sherry, S. B., Habke, M., Parkin, M., Lam, R. W., \& Stein, M. B. (2003). The interpersonal expression of perfection. Journal of Personality and Social Psychology, 84, 1303-1325. doi:10.1037/0022-3514.84.6.1303.

Hewitt, P. L., Newton, J., Flett, G. L., \& Callander, L. (1997). Perfectionism and suicide ideation in adolescent psychiatric patients. Journal of Abnormal Child Psychology, 25, 95-101. doi:10.1023/A:1025723327188

Hu, L. T., \& Bentler, P. M. (1999). Cutoff criteria for fit indexes in covariance structure analysis: Conventional criteria versus new alternatives. Structural Equation Modeling: A Multidisciplinary Journal, 6, 1-55. doi:10.1080/10705519909540118

Huang, L., Stroul, B., Friedman, R., Mrazek, P., Friesen, B., Pires, S., \& Mayberg, S. (2005). Transforming mental health care for children and their families. American Psychologist, 60, 615-627. doi:10.1037/0003-066X.60.6.615 
Huggins, L., Davis, M. C., Rooney, R., \& Kane, R. (2008). Socially prescribed and self-oriented perfectionism as predictors of depressive diagnosis in preadolescents. Australian Journal of Guidance and Counselling, 18, 182-194. doi:10.1375/ajgc.18.2.182

Jacobi, C., Hayward, C., de Zwaan, M., Kraemer, H. C., \& Agras, W. (2004). Coming to terms with risk factors for eating disorders: Application of risk terminology and suggestions for a general taxonomy. Psychological Bulletin, 130, 19-65. doi:10.1037/0033-2909.130.1.19

Joiner, T. E. (1994). Contagious depression: Existence, specificity to depressive symptoms, and the role of reassurance seeking. Journal of Personality and Social Psychology, 67, 287296.

Joiner, T. E., Jr., Katz, J., \& Lew, A. (1997). Self-verification and depression in youth psychiatric inpatients. Journal of Abnormal Psychology, 106, 608-618. doi:10.1037/00 21-843X. 106.4.608

Judd, L., Schettler, P., \& Akiskal, H. (2002). The prevalence, clinical relevance, and public health significance of subthreshold depressions. Psychiatric Clinics of North America, 25, 685-698. doi:10.1016/S0193-953X(02)00026-6

Kenney-Benson, G. A., \& Pomerantz, E. M. (2004). The role of mothers' use of control in children's perfectionism: Implications for the development of children's depressive symptoms. Journal of Personality, 73, 23-46. doi:10.1111/j.1467-6494.2004.00303.x

Kessler, R. C., Avenevoli, S., \& Merikangas, K. R. (2001). Mood disorders in children and adolescents: An epidemiologic perspective. Biological Psychiatry, 49, 1002-1014.

Kline, R. B. (2005). Principles and Practice of Structural Equation Modeling (2nd ed.). New York, NY: The Guilford

Kupersmidt, J. B., Coie, J. D., \& Dodge, K. A. (1996). The role of poor peer relationships in the 
development of disorder. In S. R. Asher, \& J. D. Coie (Eds.). Peer rejection in childhood (pp. 274-305). New York, NY: Cambridge University Press.

Little, R. (1988). A test of missing completely at random for multivariate data with missing values. Journal of the American Statistical Association, 83, 1198-1202. doi:10.1080/ 01621459.1988 .10478722

Masten, A. S. \& Cicchetti, D. (2010). Editorial: Developmental Cascades. Development and Psychopathology, 22, 491-495. doi:10.1017/S0954579410000222

McCreary, B. T., Joiner, T. E., Schmidt, N. B., \& Ialongo, N. S. (2004). The structure and correlates of perfectionism in African American children. Journal of Clinical Child and Adolescent Psychology, 33, 313-324. doi:10.1207/s15374424jccp3302_13

McGrath, D. S., Sherry, S. B., Stewart, S. H., Mushquash, A. R., Allen, S. L., Nealis, L. J., \& Sherry, D. L. (2012). Reciprocal relations between self-critical perfectionism and depressive symptoms: Evidence from a short-term, four-wave longitudinal study. Canadian Journal of Behavioural Science/Revue canadienne des sciences du comportement, 44, 169-181. doi:10.1037/a0027764

Merikangas, K. R., He, M. J. P., Burstein, M., Swanson, M. S. A., Avenevoli, S., Cui, M. L., ... \& Swendsen, J. (2010). Lifetime prevalence of mental disorders in US adolescents: Results from the National Comorbidity Study-Adolescent Supplement (NCS-A). Journal of the American Academy of Child and Adolescent Psychiatry, 49, 980-989. doi:10.1016/ j.jaac.2010.05.017

Nolen-Hoeksema, S., \& Girgus, J. S. (1994). The emergence of gender differences in depression during adolescence. Psychological Bulletin, 115, 424-443. doi:10.1037/00332909.115.3.424. 
O’Connor, R. C., Dixon, D., \& Rasmussen, S. (2009). The structure and temporal stability of the Child and Adolescent Perfectionism Scale. Psychological Assessment, 21, 437-443. doi: $10.1037 / \mathrm{a} 0016264$

O'Connor, R. C., Rasmussen, S., \& Hawton, K. (2010). Predicting depression, anxiety and selfharm in adolescents: The role of perfectionism and acute life stress. Behaviour research and therapy, 48, 52-59. doi:10.1016/j.brat.2009.09.008

Orth, U., Robins, R., \& Roberts, B. W. (2008). Low self-esteem prospectively predicts depression in adolescence and young adulthood. Journal of Personality and Social Psychology, 95, 695-708. doi:10.1037/0022-3514.95.3.695

Persons, J. B., \& Miranda, J. (1992). Cognitive theories of vulnerability to depression: Reconciling negative evidence. Cognitive Therapy and Research, 16, 485-502. doi:10. 1007/BF01183170

Reynolds, C. R., \& Kamphaus, R. W. (2004). Behavior assessment system for children - second edition manual. Minneapolis: Pearson

Rhode, P., Lewinsohn, P. M., \& Seeley, J. R. (1990). Are people changed by the experience of having an episode of depression? A further test of the "scar" hypothesis. Journal of Abnormal Psychology, 99, 264-271. doi:10.1037/0021-843X.99.3.264

Rice, K. G., \& Aldea, M. A. (2006). State dependence and trait stability of perfectionism: A short-term longitudinal study. Journal of Counseling Psychology, 53, 205-213. doi:10.1037/0022-0167.53.2.205

Rice, K. G., Leever, B. A., Noggle, C. A., \& Lapsley, D. K. (2007). Perfectionism and depressive symptoms in early adolescence. Psychology in the Schools, 44, 2, 139-156. doi:10.1002/pits.20212 
Rudolph, K. D., Flynn, M., \& Abaied, J. L. (2008). A developmental perspective on interpersonal theories of youth depression. In J. R. Z. Abela \& B. L. Hankin (Eds.), Child and adolescent depression: Causes, treatment, and prevention (pp. 79-102). New York: Guilford.

Salmela-Aro, K., \& Nurmi, J. (1996). Depressive symptoms and personal project appraisals: A cross-lagged longitudinal study. Personality and Individual Differences, 21, 373-381. doi: 10.1016/0191-8869(96)00078-5

Scott, K. M., Von Korff, M., Angermeyer, M. C., Benjet, C., Bruffaerts, R., de Girolamo, G., ... \& Kessler, R. C. (2011). Association of childhood adversities and early-onset mental disorders with adult-onset chronic physical conditions. Archives of General Psychiatry, 68, 838-844. doi:10.1001/archgenpsychiatry.2011.77

Segal, Z. V., \& Ingram, R. E. (1994). Mood priming and construct activation in tests of cognitive vulnerability to unipolar depression. Clinical Psychology Review, 14, 663-695. doi:10. 1016/0272-7358(94)90003-5

Shahar, G., Blatt, S. J., Zuroff, D. C., Kuperminc, G. P., \& Leadbeater, B. J. (2004). Reciprocal relations between depressive symptoms and self-criticism (but not dependency) among early adolescent girls (but not boys). Cognitive Therapy and Research, 28, 85-103. doi: 10.1023/B:COTR.0000016932.82038.d0

Slaney, R. B., Rice, K. G., Mobley, M., Trippi, J., \& Ashby, I. (2001). The revised almost perfect scale. Measurement and Evaluation in Counselling and Development, 34, 130145.

Sherry, S. B., Mackinnon, S. P., Macneil, M. A., \& Fitzpatrick, S. (2012). Discrepancies confer 
vulnerability to depressive symptoms: A three-wave longitudinal study. Journal of Counseling Psychology. 60, 112-126. doi:10.1037/a0030439

Soenens, B., Luyckx, K., Vansteenkiste, M., Luyten, P., Duriez, B., \& Goossens, L. (2008). Maladaptive perfectionism as an intervening variable between psychological control and adolescent depressive symptoms: A three-wave longitudinal study. Journal of Family Psychology, 22, 465-474. doi:10.1037/0893-3200.22.3.465

Stoeber, J., Otto, K., \& Dalbert, C. (2009). Perfectionism and the big five: Conscientiousness predicts longitudinal increases in self-oriented perfectionism. Personality and Individual Differences, 47, 363-368. doi:10.1016/j.paid.2009.04.004

Teasdale, J. D. (1983). Negative thinking in depression: Cause, effect, or reciprocal relationship? Advances in Behavior Research and Therapy, 5, 3-25. doi:10.1016/0146-6402(83)900 $13-9$

Tram, J. M., \& Cole, D. A. (2006). A multimethod examination of the stability of depressive symptoms in childhood and adolescence. Journal of Abnormal Psychology, 115, 674-686. doi:10.1037/0021-843X.115.4.674

Weisz, J. (1998). Effects of psychopathology with children and adolescents: What we know and what we need to learn. In D. Cicchetti, S. L., Toth, (Eds.), Rochester symposia on developmental psychopathology: Vol. 9. Developmental approaches to prevention and intervention (pp. 22-49). Rochester, NY: University of Rochester Press.

Yamamoto, Y., \& Holloway, S. D. (2010). Parental expectations and children's academic performance in sociocultural context. Educational Psychology Review, 22, 189-214. doi: $10.1007 / \mathrm{s} 10648-010-9121-\mathrm{z}$

Zuroff, D. C., Blatt, S. J., Sanislow, C. A., Bondi, C. M., \& Pilkonis, P. A. (1999). Vulnerability 
to depression: Reexamining state dependence and relative stability. Journal of Abnormal Psychology, 108, 76-89. doi:10.1037/0021-843X.108.1.76 
Table 1

Bivariate Correlations

\begin{tabular}{llllllll}
\hline 1 & 2 & 3 & 4 & 5 & 6 & 7
\end{tabular}

Grade 6
1 DEP

Grade 7

$\begin{array}{llllll}2 & \text { SOP } & -.01 & - & & \\ 3 & \text { SPP } & .16 * * & .54 * * & - & \\ 4 & \text { DEP } & .61 * * & .11 * & .29 * * & -\end{array}$

Grade 8

$\begin{array}{lllllllll}5 & \text { SOP } & -.02 & -.66^{* *} & .33 * * & .05 & - & \\ 6 & \text { SPP } & .17^{* *} & .38^{* *} & .60 * * & .23 * * & .50^{* *} & - & \\ 7 & \text { DEP } & .41 * * & .01 & .16^{* *} & .52 * * & .08 & .28 * * & -\end{array}$

Note. $\mathrm{DEP}=$ depression, $\mathrm{SOP}=$ self-oriented perfectionism, $\mathrm{SPP}=$ socially prescribed perfectionism. $*=p<.05, * *$ $=p<.01$. 
Table 2

Means and SD and Sex Difference Tests

\begin{tabular}{ccccccc}
\multicolumn{2}{c}{ Boys } & \multicolumn{2}{c}{ Girls } & Test & \multicolumn{2}{c}{ Total } \\
$M$ & $S D$ & $M$ & $S D$ & $F$ & $M$ & $S D$
\end{tabular}

Grade 6

$\begin{array}{llllllll}\text { DEP } & 3.97 & 4.70 & 4.64 & 5.48 & 2.64 & 4.32 & 5.13\end{array}$

Grade 7

$\begin{array}{llllllll}\text { SOP } & 22.76 & 8.29 & 21.98 & 8.90 & 1.06 & 22.33 & 8.62 \\ \text { SPP } & 12.06 & 8.16 & 11.20 & 8.11 & 1.46 & 11.60 & 8.14 \\ \text { DEP } & 2.72 & 3.89 & 4.26 & 5.18 & 14.78^{* *} & 3.56 & 4.70\end{array}$

Grade 8

$\begin{array}{llllllll}\text { SOP } & 23.11 & 9.11 & 23.92 & 9.82 & 0.89 & 23.57 & 9.52 \\ \text { SPP } & 12.58 & 8.49 & 12.62 & 8.66 & 0.00 & 12.60 & 8.58 \\ \text { DEP } & 2.95 & 4.10 & 4.61 & 5.33 & 14.57^{* *} & 3.88 & 4.89\end{array}$

Note. $\mathrm{DEP}=$ depression, $\mathrm{SOP}=$ self-oriented perfectionism, $\mathrm{SPP}=$ socially prescribed perfectionism. $* *=p<.01$. 
Table 3

Model Fit and Comparisons Statistics

\begin{tabular}{|c|c|c|c|c|c|c|c|c|c|}
\hline \multirow[b]{2}{*}{ Model } & \multicolumn{4}{|c|}{ Fit Statistics } & \multicolumn{5}{|c|}{ Difference Tests } \\
\hline & $\chi^{2}$ & $d f$ & CFI & RMSEA $(90 \%$ CI) & AIC & vs. & $\Delta \chi^{2}$ & $\Delta d f$ & $\Delta \mathrm{CFI}$ \\
\hline 1.Vulnerability & $39.397 * *$ & 7 & .973 & $.084(.060-.111)$ & 95.397 & 3 vs. 1 & $31.572 * *$ & 4 & .023 \\
\hline 2. Scar & $11.320^{*}$ & 5 & .995 & $.044(.006-.079)$ & 71.320 & & & & \\
\hline $\begin{array}{l}\text { 3. Reciprocal- } \\
\text { causality }\end{array}$ & 7.825 & 3 & .996 & $.050(.001-.094)$ & 71.825 & 3 vs. 2 & 3.495 & 2 & .001 \\
\hline
\end{tabular}

Sex differences in scar model

$\begin{array}{llllll}\text { 4. Sex specific } \quad 17.595 & 10 & .994 & .034(.000-.060) & 137.595\end{array}$

$\begin{array}{llllllllll}\text { 5. Sex invariant } & 21.396 & 14 & .994 & .010(.000-.051) & 133.396 & 4 \text { vs. } 5 & 3.801 & 4 & .000\end{array}$

Final model

$\begin{array}{llllllllll}\text { 6. Trimmed scar } & 12.890 & 8 & .996 & .031(.000-.060) & 66.890 & 6 \text { vs. } 2 & 1.570 & 3 & .001\end{array}$

Note: $\mathrm{CFI}=$ comparative fit index. RMSEA $=$ root mean square error of approximation. $\mathrm{AIC}=$ Akaike information criterion. $*=p<.05, * *=p<.01$. 

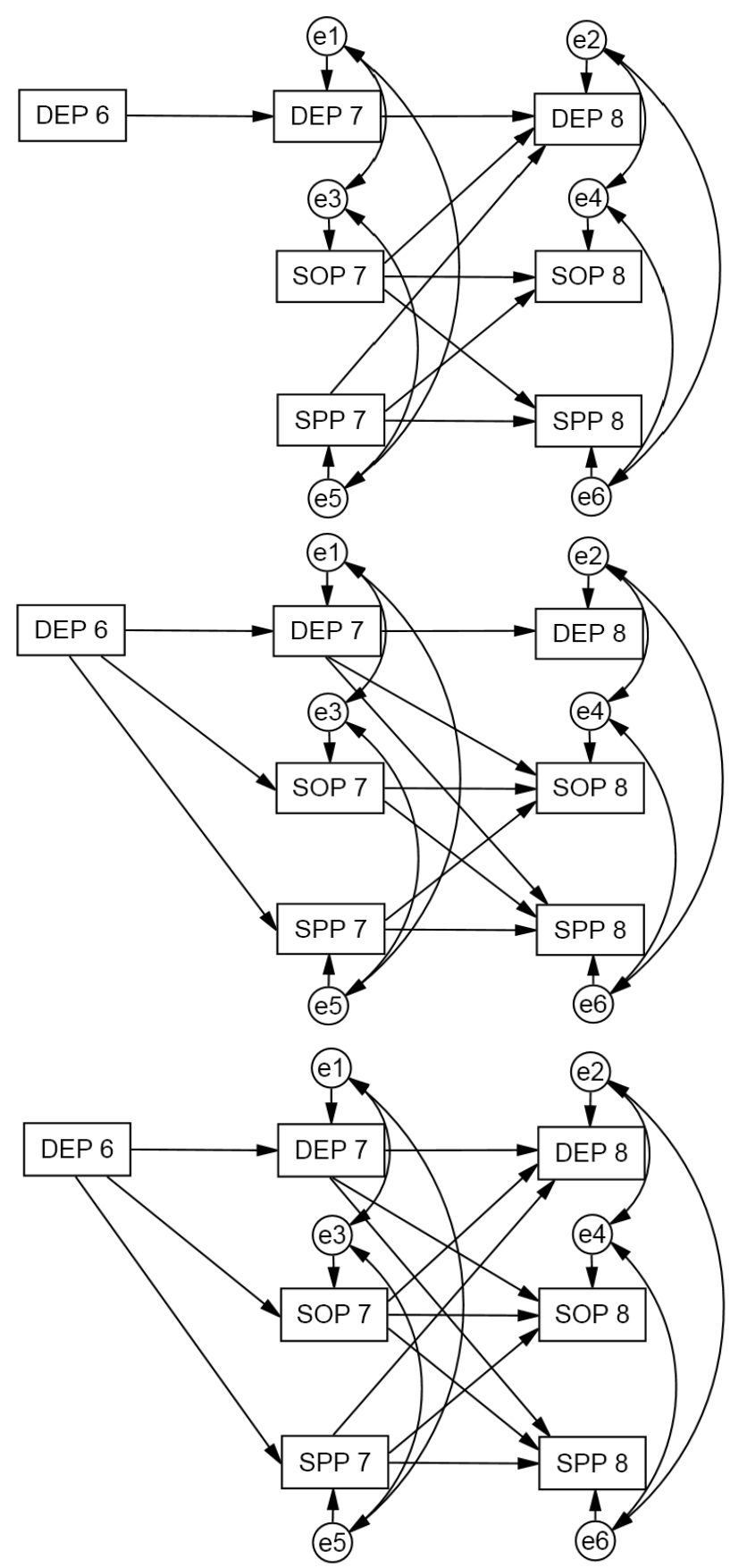

Figure 1. Conceptualization of the three competing models. The vulnerability model (top) assumes that depression is an outcome of perfectionism. The scar model (middle) assumes that perfectionism is an outcome of depression. The reciprocal-causality model (bottom) assumes that the perfectionism and depression simultaneously influence each other. In all models, we controlled for: within-time correlations between the variables, the potential effects of the interrelation between SOP and SPP over time, as well as prior depressive symptoms, SOP, and SPP. DEP = depression. SOP = self-oriented perfectionism. SPP = socially prescribed perfectionism. 


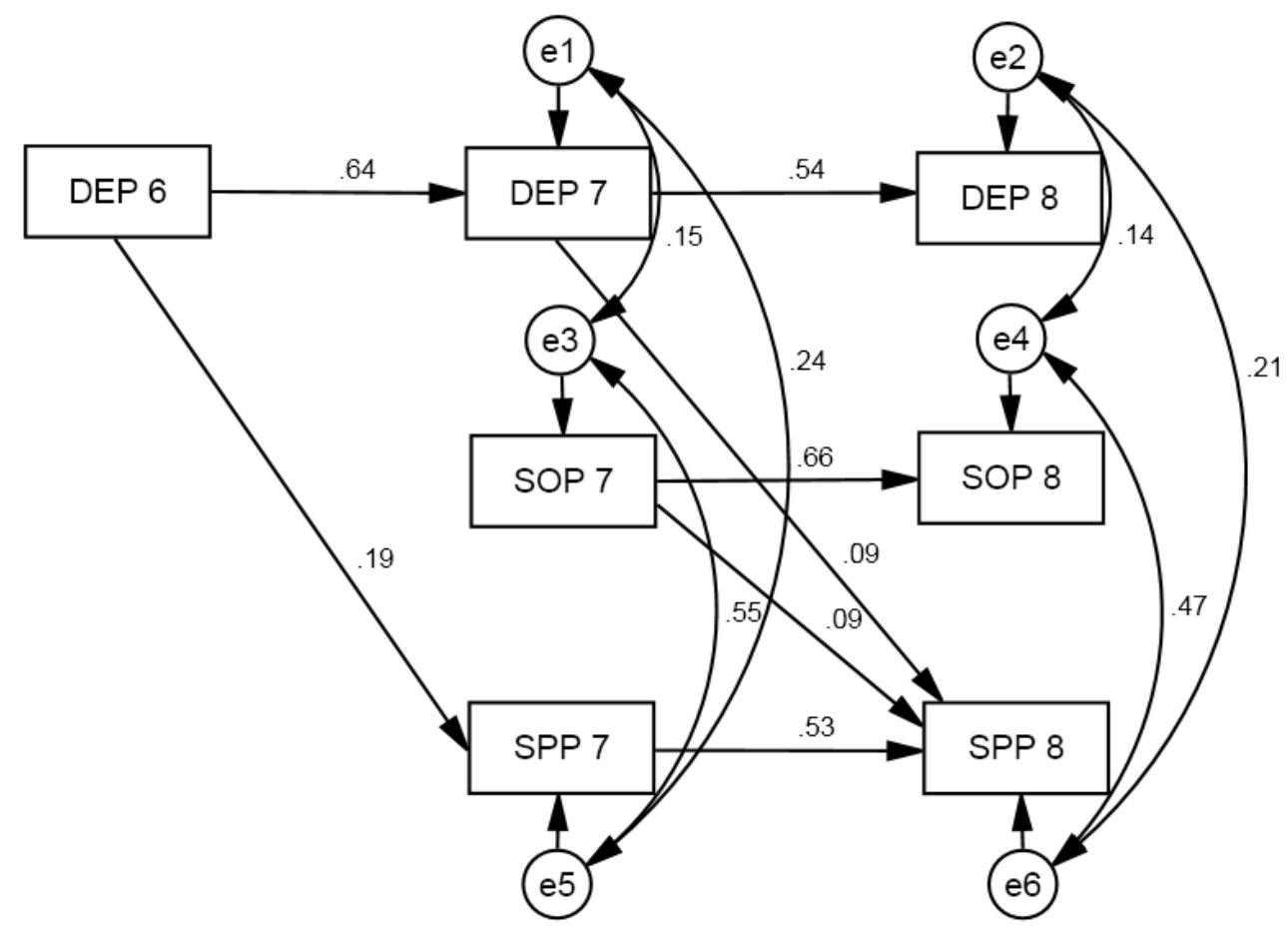

Figure 2. Final model (trimmed scar model) with statistically significant standardized path coefficients and within time correlations $(p<.05)$, controlling for the cross-sectional relation between the variables, the potential effects of the interrelations between SOP and SPP across time, as well as prior depressive symptoms, SOP, and SPP. DEP = depression. SOP = self-oriented perfectionism. SPP = socially prescribed perfectionism. 